\title{
SUSTAINABLE DEVELOPMENT OF GREEN BUILDING BASED ON INTUITIONISTIC FUZZY ANALYTIC HIERARCHY PROCESS
}

\author{
HUANG, Y., ${ }^{1,2}-$ WU, W. ${ }^{2}-$ YANG, S. ${ }^{1,2^{*}}$ \\ ${ }^{\text {I}}$ Zhuhai College of Jilin University \\ Caotang Crescent (Wan), Jinwan District, Zhuhai City 519041, China \\ ${ }^{2}$ Faculty of Innovation and Design, City University of Macau \\ Avenida Padre Tomás Pereira Taipa, Macau City 999078, China \\ *Corresponding author \\ e-mail: samyang8747@qq.com; phone/fax: +86-177-6523-4675; fax: +86-853-6523-4675
}

(Received $18^{\text {th }}$ Sep 2018; accepted 26 $6^{\text {th }}$ Nov 2018)

\begin{abstract}
A city is an area highly concentrated in buildings, but is also an important place for energy consumption and waste generation, so the development of buildings with low energy consumption and less pollutant emissions is an important way to achieve energy conservation and emission reduction, and sustainable development of cities in China. On the basis of systematically combing and broadly absorbing the relevant research results of sustainable development and urban greening, and combining with the mathematical methods such as variation coefficient and intuitionistic fuzzy analytic hierarchy process, urban housing buildings are taken as the subject of evaluation. With sustainable development as the evaluation background, the aim of study is to systematically and comprehensively evaluate and analyze the building greening level. Based on the analysis of green building theory and predecessors' research results, the influence of economic, political, technical and other factors on the development of green building in nearly 300 cities in China is analysed. And combined with the actual development examples of Shenzhen City, it is further discussed. It is concluded that the research method used in this paper is correct, and Shenzhen is selected as an example to provide reference for the sustainable development of other cities
\end{abstract}

Keywords: sustainable development, Chinese architecture, green building, Shenzhen, greening evaluation methods

\section{Introduction}

As the population grows rapidly, resources are wasted and consumed, the environment is destroyed, and the new concept of sustainable development is gradually formed. More and more people are paying attention to environmental protection, green, health and ecological balance. From experts and scholars to the public are calling for taking good care of the environment, saving resources and avoiding waste, and doing their part and responsibility for the sustainable development of the society. The concept of green building is the important direction of the development of building energy efficiency is an important measure to speed up the change pattern of urban and rural construction in China, is also an important means of sustainable development in our country in the future. It analyze that influence of economic environment, policy environment and technology environment on the basis of difference in the construction of green build, and has a certain research value for the future city green build and the sustainable development of city (Zhu et al., 2016). 


\section{Research background and motivation}

Since the transformation of human society from agriculture to industrialization, great changes have taken place in production and lifestyle. On the one hand, it has greatly improved people's living conditions, promoted rapid economic growth and enriched human material and cultural life. However, at the same time, human sustainable development is facing new problems, the contradictions among the ecosystem of people and earth, living environment and natural resources are becoming increasingly acute, mainly manifesting in: forest destruction, desertification, global energy crisis, and environmental pollution. These problems have gradually become a hot issue of common concern around the world. As Qiu Baoxing, chairman of the Chinese Academy of Urban Sciences, said, "the most successful thing in China's industrial civilization in the past has also become the biggest obstacle to China's urban green development". Therefore, it is necessary to abandon the extensive development in the thinking of industrial civilization and the rigid mode of mass production in life. Only by abandoning this extensive economic characteristic of seeking economic development by sacrificing the environment can sustainable development be realized from the source. But sustainable development and ecological civilization are not totally denying industrial civilization, but the new stage and new form of self-adjustment and self-development of industrial civilization. They are not overflowing the historical period of industrial civilization. In essence, they are the ecological reconstruction of industrial civilization. They are based on industrial civilization and coordinate the sustainability between the two aspects of economy and environment.

The Eighteenth National Congress of the Communist Party of China included the concept of scientific development in the Party's guiding ideology ( $\mathrm{Hu}, 2018)$, and clearly put forward that it is necessary to consciously take comprehensive, coordinated and sustainable development as the basic requirements for the in-depth implementation of the concept of scientific development. In 2015, the Fifth Plenary Session of the Eighteenth Central Committee once again sounded the horn of green development (Yang, 2016), and put forward a series of new measures to achieve green development. In 2017, the report of the Nineteenth National Congress pointed out that it is necessary to establish and practice the concept of "green water and green mountains are golden mountains and silver mountains". It pointed out the direction for the construction of ecological civilization and paid great attention to ecological civilization and green development. Under the strong call of the state on sustainable development, green development and ecological civilization ( $\mathrm{Hu}, 2018)$, all walks of life in the production process are also actively responding.

According to the classification of national economic industries, issued with the approval of the general administration of quality supervision, inspection and quarantine and the standardization administration of China, and implemented on November 1, 2011, construction industry, as one of the important pillar industries, has played a great role in promoting the rapid development of China's economy. But the construction industry has made such an important contribution to our economy, at the same time, the damage to our energy, resources and environment cannot be underestimated. According to the China Building Energy Consumption Research Report (2017), China's total building energy consumption in 2015 accounted for $20 \%$ of the total national energy consumption; housing construction consumed $1 / 3$ of the total steel in the whole life cycle, and urban water and construction land also reached $1 / 3$ of the total. In addition, in 
terms of building energy consumption, there is a certain proportion of growth every year, and the phenomenon is obvious.

According to the China Environmental Situation Bulletin 2016 published in June 2017, of the 338 cities in China, the air quality in 254 cities exceeded the standard, accounting for $75.1 \%$ of the total cities in the country, while the number of cities meeting the standard was only $24.9 \%$. Although the air quality in China is gradually improving compared with that in 2015 , from the ratio of air quality in 338 cities shown in Figure 1, it can be seen that, in terms of China's environmental air condition, China is facing more complex and serious environmental quality problems and the task is still very arduous.

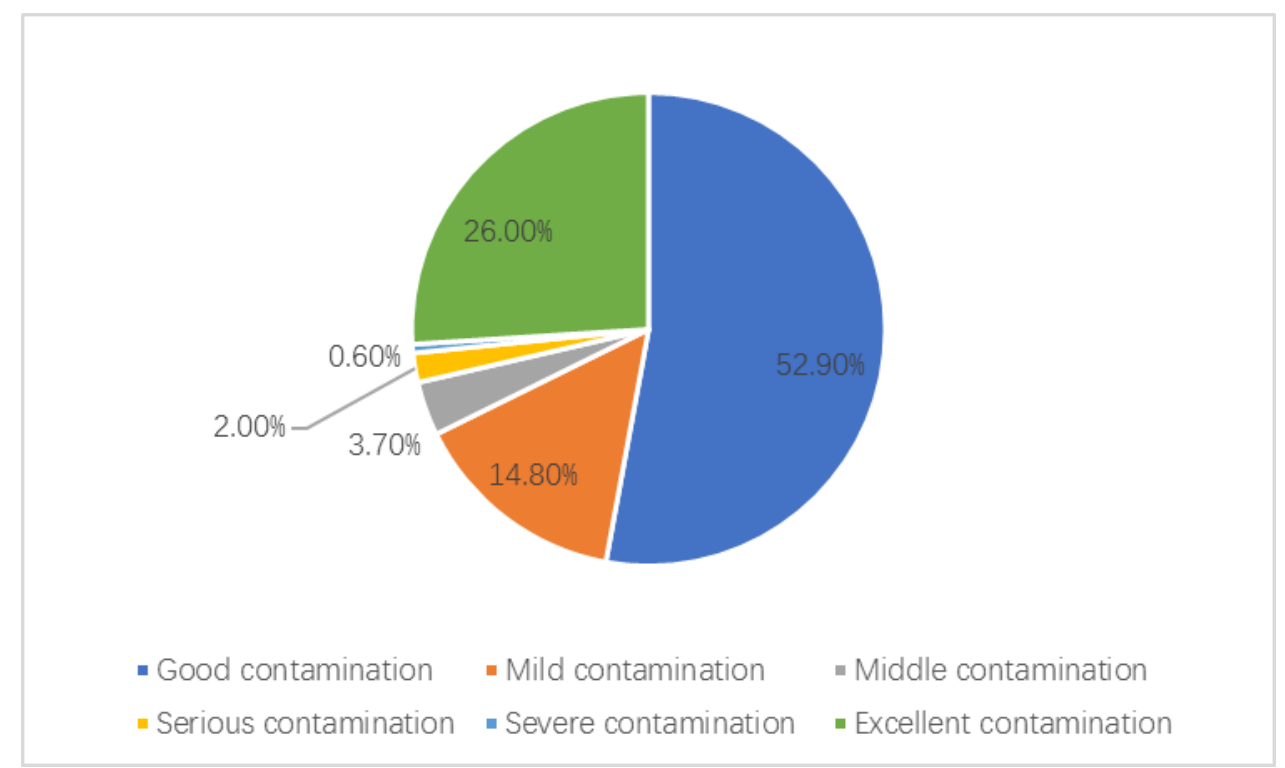

Figure 1. Proportion of environmental air quality in 338 cities of China in 2016, the data comes from China Environmental Situation Bulletin

China is in a critical period of new urbanization construction, most cities will be built on a large scale in the future, and the sustainable development of the construction field is related to the sustainable development of the whole society. Therefore, green building is an important development direction of building energy conservation in the future, an important grasp to speed up the transformation of urban and rural construction mode, but also an important means of sustainable development in China's future. The development of green building is affected by all aspects of the city (Yang and Zhou, 2010). It has become an important topic to be discussed urgently what guaranteeing and encouraging measures the city should take to more effectively promote the construction of green building and promote the overall sustainable development of the region (Huang and Shi, 2016).

\section{Materials and methods}

\section{Basic theories of sustainable development}

With the rapid growth of population, the gradual reduction of resources and the increasing destruction of the environment, the new concept of sustainable development 
has gradually come into being. "Some works" have laid a preliminary foundation for the formation of sustainable theory and made a systematical study of the problems faced by the long-term economic development of mankind. They include Silent Spring published by Rachel Carson, American marine biologist, in 1962, the report of Limits to Growth submitted by a group of 17 people led by Dennis in Massachusetts Institute of Technology in 1972, Blueprint for Survival submitted by E. Goldsmith, British ecologist, in 1972 and other works. These reports profoundly analyze the problems in the process of human development and the importance of sustainable development. In 1987, the World Commission on Environment and Development (WECD) submitted Our Common Future to the UN General Assembly and formally proposed the concept and model of "sustainable development" (Wuelser and Pohl, 2016). In this investigation report, human development is closely combined with ecological environment and sustainable development is defined as the development of the ability to meet the needs of contemporary people without harming the development needs of future generations.

The proposal of sustainable development is a profound reflection of human beings on the status quo of the ecological environment, which has been unanimously recognized by the international community since its formation (Takahashi, 2017). Its meaning can also be explained from the following four perspectives. From the perspective of economics, sustainable development is to achieve the highest net benefits under the premise of ensuring the rational use of resources and ensuring that the ecological environment is not destroyed (Sharma et al., 2016). From the perspective of sociology, sustainable development is to "improve the quality of human life without exceeding the capacity to maintain ecosystem tolerance". Human survival and the earth's carrying capacity and biodiversity achieve harmonious unity and co-existence, which is also mentioned in the Survival Strategy. From the perspective of natural ecology, sustainable development is the coordinated balance between natural resources and ecological environment system, and it satisfies the sustainable survival of human beings in an optimal balance state (Aggarwal and Singh, 2018). From the perspective of science and technology, sustainable development is to adopt new technologies and techniques that can save resources and reduce environmental pollution. From the perspective of scientific and technological innovation, it can not only meet the original intention of economic development and social needs (Tao et al., 2009), but also achieve the purpose of sustainable utilization of living environment and natural resources, so as to achieve the coordination of the three (Rahmati et al., 2016).

Since 2006, the total output value of "China's construction industry" has been continuously increasing, its annual value-added since 2009 has reached $6.5 \%$ of GDP, and its position is stable. As an extremely important branch of the construction industry, the consumption of energy, materials, water resources and land occupancy of housing construction industry is even greater in the whole process of production and management (Rodríguez et al., 2016). According to incomplete statistics, about half of the global energy and materials are consumed by the housing construction industry. According to the "Analysis Report of Market Prospects and Investment Strategic Planning of China's Intelligent Building Industry" from 2013 to 2017, the total energy consumption of China's housing construction is increasing year by year, accounting for nearly $30 \%$ of the total energy consumption (Shafie et al., 2017). The whole process of building activities causes rapid deterioration of the ecological environment and heavy energy burdens. Therefore, facing the sustainable development, in the process of building production, saving resources and strengthening the recycling of materials and 
waste disposal in the construction process will play an important role in building a "two-oriented society" in China (Baden and Prasad, 2016).

Sustainable development of "housing construction enterprises" should run through the whole process of preparing, planning, design, construction and maintenance after use. Every link from land use, building materials use, production process use and so on will be implemented specifically to save resources and avoid pollution.

\section{Sustainable development and green building}

Under the background of the rapid development of global urbanization in the 21st century, the key problem of sustainable development lies in the sustainable development of urban areas (Chong and Wang, 2016). How to transform the concept of sustainable development into urban practice to effectively promote urban sustainable development is undoubtedly a hot topic in sustainable development today. One of the core issues of sustainable development is resources and environment, which is embodied as the mode of energy-saving, environmental protection and ecological development in "urban development" (Wang, 2017). In the past two decades, China's construction industry has shown explosive growth, but due to the lack of awareness of sustainable development, the construction industry in China has always been a "high energy consumption and high pollution" industry (Shengshi Zhou, 2010).

- According to statistics, the resources consumed in the whole process of building activities (building materials production, construction, use, waste disposal, etc.) ranked first in all industries (Yuan et al., 2017). Sustainable development of construction industry means to integrate the concept of sustainable development into every link of construction, to save energy, reduce pollution, and improve the ecological and environmental benefits of buildings as much as possible. From this point of view, the sustainable development of the construction industry plays an important role in promoting urban sustainable development (Edgren, 2016).

"Green building" is a response to the concept of sustainable development in the field of building, and it is also one of the strategic means to achieve sustainable development in cities. At present, there is no uniform definition of green building in the world. The definition and connotation of green building are defined by the Green Building Evaluation Criteria formulated in 2006 - "buildings that can save resources (energy, land, water and materials), protect the environment, reduce pollution, provide people with healthy, applicable and efficient use space, and harmoniously live with nature in the whole life cycle" (Wu et al., 2017). The revised Green Building Evaluation Criteria (2014) retains the original definition of green building and adds green civil buildings to residential and public buildings based on office buildings, shopping malls and hotels (Xiu et al., 2017). Green building stresses saving resources, reducing pollution and harmonious coexistence between man and nature (Wu et al., 2016). These concepts are highly consistent with the concept of sustainable development. With the widespread concern of the concept of sustainable development of building in China, the importance of green building development in China's construction industry has been greatly enhanced.

\section{Evaluation method of green housing construction facing sustainable development}

Generally speaking, there are many greening evaluation methods: fuzzy comprehensive evaluation method, neural network evaluation method, fuzzy analytic 
hierarchy process, and intuitionistic fuzzy analytic hierarchy process (Alwan et al., 2017). In order to make this greening evaluation more scientific and reasonable, their advantages and disadvantages will be elaborated.

Fuzzy comprehensive evaluation method comes from the application of fuzzy mathematics theory (Pang et al., 2016). Based on membership degree theory, the factors of qualitative evaluation and those factors with fuzzy boundary and difficult to quantify are transformed into quantitative evaluation, and then comprehensive evaluation is made on the things to be evaluated (Brown, 2016). The basic idea of fuzzy comprehensive evaluation method is to establish factor set and comment set firstly; then, after the weight vectors of each evaluation index are determined, the evaluation matrix of each index is expressed by membership degree vector; and then the weights and evaluation matrix are synthetically calculated, and from the first level to the highest level, according to the principle of maximum membership, the final results of fuzzy comprehensive evaluation are obtained (Broman and Robèrt, 2017). This method can transform qualitative indicators into quantitative indicators, which has strong practicability and strong correlation among various evaluation steps, and it is widely used in things or objects restricted by many factors (Baishou and Gao, 2017). However, this method has strong subjectivity in the process of determining the weight of indicators, which makes the evaluation results easy to be affected and its reliability is reduced (Staffordsmith et al., 2017).

"Intuitionistic fuzzy analytic hierarchy process" is an organic combination of "intuitionistic fuzzy set theory" and "analytic hierarchy process". On the basis of the above "fuzzy analytic hierarchy process" (Zhang et al., 2012), this method adds the information of non-membership degree. Its basic ideas are: to clarify the relationship among the factors of the object to be evaluated, to establish an evaluation hierarchical structure model; to compare the importance of each factor (Kopnina, 2016); to establish an intuitionistic fuzzy complementary judgment matrix (Yang et al., 2012); to test the consistency of the intuitionistic fuzzy complementary judgment matrix; to determine the weights of indicators at all levels; and finally to get the evaluation grade level results. This method is the extension of fuzzy theory. The attitude of support, opposition and neutrality is more fully reflected in the process of weight calculation. It is more in line with people's subjective judgment thinking and it is the application extension of fuzzy mathematics in the greening evaluation process of housing construction enterprises. It is more flexible and persuasive to deal with the contradiction between forecasting and reality caused by human subjectivity, making the greening evaluation more objective (Kopnina, 2017).

\section{Results}

\section{Analysis of factors influencing the greening of housing construction}

The domestic and foreign literature on the study of the factors affecting the greening of housing construction can be divided into the following four categories.

Greening concept. What can provide realistic solutions to the disharmonious development between man and nature is called greening concept. As an important pillar industry in social production, housing construction industry is not only the provider of material information, but also its producer. Enterprise's strategy in environmental protection can directly affect the ecological environment of the place where the enterprise is located. 
Greening capability. The foundation of greening capability is the green resources owned by enterprises. There are certain forms and objective existence of resources, but the former is invisible but active. Although the two concepts are different, they are closely related and can be transformed into each other.

Greening environmental benefits. Environmental friendliness is affected by a series of aspects such as efficient utilization of material, resources, and energy and waste disposal. Therefore, low consumption and emission reduction, high efficiency and environmental protection, as well as integration and optimization are the basic direction of the future development of China's housing construction industry.

Greening economic benefits. The greening evaluation of housing construction enterprises is closely related to the factors such as market share, profit growth rate, asset return rate and the proportion of green building development. At the same time, the green economy is also included in the greening evaluation. The collection of these factors is the greening economic benefits, which can also be defined as the dominant benefit of green building.

Through the analysis of the above content, the greening impact factors of green housing construction can be assumed, as shown in Figure 2. Greening concept, greening capability, greening environmental benefits and greening economic benefits these four elements work together on the green development of housing construction. At the same time, ideas and capabilities also play a role in promoting environmental and economic benefits; in addition to the interaction between environmental and economic benefits, the two will turn into greening ideas and greening capabilities. In this way, the five of them complement each other and influence each other.

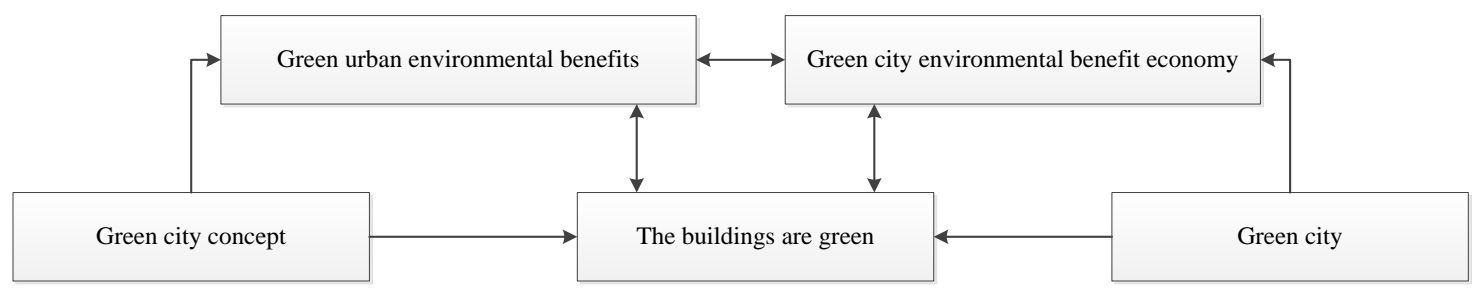

Figure 2. The elements influencing the greening of buildings. The above factors are summarized from the relevant domestic and foreign literature

\section{Establishment of greening evaluation model for housing construction}

\section{(1) Building a hierarchical structure model}

Through the above analysis and study of the factors affecting the greening of housing construction, the links between the various factors are clarified to stratify and establish a hierarchical structure model, as shown in Figure 3.

\section{(2) Establishment of intuitionistic fuzzy complementary judgment matrix}

The degree of importance of each factor is two-two compared with that of intuitionistic fuzzy judgment matrix (Yi and Zhao, 2013; Eq. 1).

$$
A=\left(a_{i j}\right)_{n \times n}
$$



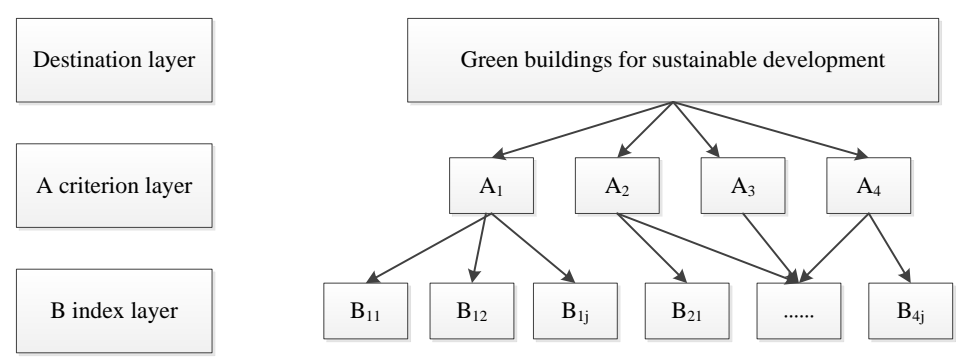

Figure 3. The hierarchical structure model of evaluation, through the above analysis and study of the factors affecting the greening of housing construction

When comparing the importance of the factors, the definition scale as shown in Table 1 is adopted.

Table 1. Definition scale of the importance of the attribute

\begin{tabular}{c|c}
\hline Evaluation grade & Intuitionistic fuzzy number \\
\hline Factor i is extremely important than factor j. & $(0.90,0.10,0.00)$ \\
Factor i is strongly important than factor j. & $(0.80,0.15,0.05)$ \\
Factor i is obviously important than factor j. & $(0.70,0.20,0.10)$ \\
Factor i is slightly important than factor j. & $(0.60,0.25,0.15)$ \\
Factor i is as important as factor j. & $(0.50,0.30,0.20)$ \\
Factor i is relatively not important than factor j. & $(0.40,0.45,0.15)$ \\
Factor i is not important than factor j. & $(0.30,0.60,0.10)$ \\
Factor i is rather important than factor j. & $(0.20,0.75,0.05)$ \\
Factor i is extremely no more important than factor j. & $(0.10,0.90,0.00)$ \\
\hline
\end{tabular}

\section{(3) Consistency test of intuitionistic fuzzy complementary judgment matrix}

According to the intuitionistic fuzzy complementary judgment matrix established in (2), we need to test its consistency. The following consistency test formula is given (Eq. 2):

$$
d(\overline{\mathrm{A}}, A)=\frac{1}{2(n-1)(n-2)} \sum_{i=1}^{n} \sum_{j=1}^{n}(|\bar{u}-u|+|\bar{V}-v|)
$$

In Equation 2, A refers to the intuitionistic fuzzy judgment matrix obtained from the two-two comparison of indexes in each layer, $A=\left(a_{i j}\right)_{n \times n} ; \overline{\mathrm{A}}$ suggests the intuitionistic fuzzy consistent judgment matrix calculated through $\mathrm{A}, A=\left(a_{i j}\right)_{n \times n}$.

\section{(4) Calculation of the weight of judgment matrix}

The vector of the first level index is known as: $A=\left(a_{1}, a_{2}, \ldots, a_{n}\right)$, $a_{i}=\left(u_{i}, v_{i}\right)(i=1,2, \ldots, n)$ is the form of intuitionistic fuzzy numbers, $u_{i}$ is an indicator of the importance of target decision making, and $\mathrm{v}_{\mathrm{i}}$ is the not important degree of indicator to target decision-making. The following formula $(E q .3)$ is applied to calculate relative weights. 


$$
W^{T}=\left[W_{1} W_{2} \ldots W_{n}\right]=\left[\frac{\sum_{j=1}^{n} a_{1 j}}{\sum_{i=1}^{n} \sum_{j=1}^{n} a_{i j}} \frac{\sum_{j=1}^{n} a_{a_{2 j}}}{\sum_{i=1}^{n} \sum_{j-1}^{n} a_{i j}} \ldots \frac{\sum_{j=1}^{n} a_{i j}}{\sum_{i=1}^{n} \sum_{j=1}^{n} a_{i j}}\right]
$$

\section{(5) Determination of membership matrix $R$}

After judging the indicators $\mathrm{A}_{\mathrm{i}}(\mathrm{i}=1,2,3,4)$ on by one, the initial membership matrix $\mathrm{R}$ of the index level factor set can be obtained (Eq. 4).

$$
R=\left[\begin{array}{l}
r_{11} r_{12} \ldots r_{1 j} \\
r_{21} r_{21} \ldots r_{2 j} \\
\ldots \\
r_{i 1} r_{i 2} \ldots r_{i j}
\end{array}\right]
$$

In Equation 4, the membership of qualitative index is directly evaluated by experts. Five language variables: "excellent", "good", "moderate", "comparatively poor" and "poor" are set up in the qualitative indexes $b_{11}, b_{12}$ and $b_{13}$ for experts to choose. The method used here is fuzzy statistics, that is, according to the survey results, the frequency of the index occurring in a certain evaluation grade is sued as its membership. In addition, qualitative indicators such as $b_{4}$ and $b_{16}$ are evaluated with two language variables "yes" and "no" and are expressed with two scores of 1 and 0 , respectively.

As for the determination of the membership degree of quantitative index, triangular fuzzy function is used as the membership function of quantitative index in order to determine its membership degree. The concrete steps of constructing triangular fuzzy function are:

Firstly, collect and determine the value of the same index in different cities and get the maximum value $a$ and the minimum value $b$ of the index as the critical interval [a, b] of the index, and three equidistant points $\mathrm{y}_{1}, \mathrm{y}_{2}$ and $\mathrm{y}_{3}$ are inserted between them. The distance $d=(b-a) / 4$ is used to calculate the membership function of the index $B_{i j}$ belonging to grade $\mathrm{E}_{\mathrm{t}}$.

(6) Intuitionistic fuzzy comprehensive evaluation

Finally, the total score is calculated according to the score formula (Eq. 5):

$$
S=W \bullet R=\left(W_{1}, W_{2}, W_{3}, \ldots, W_{n}\right) \bullet R
$$

It can be specifically evaluated according to Table 2 .

Table 2. Green evaluation standard for housing construction enterprises based on sustainable development

\begin{tabular}{c|c|c|c|c|c}
\hline & $\begin{array}{c}\text { Supper excellent } \\
\text { greening city }\end{array}$ & $\begin{array}{c}\text { Excellent } \\
\text { greening city }\end{array}$ & Greening city & $\begin{array}{c}\text { Relative greening } \\
\text { city }\end{array}$ & $\begin{array}{c}\text { Not } \\
\text { identified }\end{array}$ \\
\hline $\begin{array}{c}\text { Evaluation } \\
\text { value }\end{array}$ & {$[1,0.8]$} & {$[0.8,0.6]$} & {$[0.6,0.4]$} & {$[0.4,0.2]$} & {$[0.2,0]$} \\
\hline
\end{tabular}


As can be seen from Table 2, if the evaluation value is between 1 and 0.8, it indicates that the city belongs to the super excellent greening city; if the evaluation value is between 0.8 and 0.6 , it indicates that the city belongs to the excellent greening city... Evaluate in this way.

\section{Discussion}

\section{Discussion of the weight value (Wi) of each criterion}

The purpose of this study is to understand the impact of urban economic, policy, social and other environmental differences on green building construction. The development differences of green building in China have been studied before, and then the influence of various environmental factors on the development of green building will be discussed. A number of independent variable data of economic, policy, social and other factors on behalf of the above influencing factors studied are collected and collocated. Through multiple regression analysis, the influencing relationship of independent variable data on the dependent variable data of the development of green building is clarified, and then the multiple regression results are studied and analyzed.

\section{Analysis framework construction}

In order to verify the impact factors analyzed above and their corresponding indicators and urban green building construction related impact relationship, a complete analysis framework is drawn up, to achieve the purpose of this study through regression model estimation and test. The analytical framework developed is shown in Figure 4.

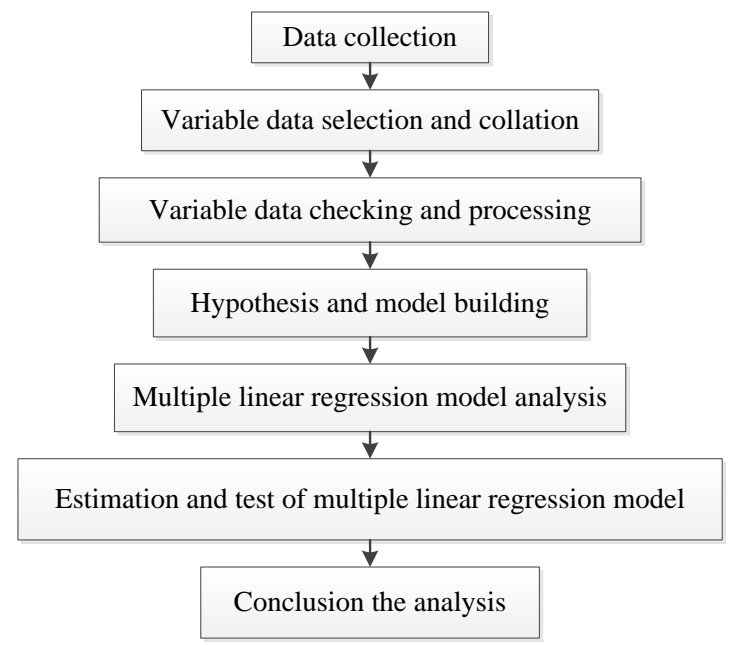

Figure 4. Regression analysis architecture diagram, in order to verify the impact factors analyzed above and their corresponding indicators and urban green building construction related impact relationship

The framework of regression analysis is divided into 7 steps. The first and the second steps are, based on the influencing factors obtained through the above analysis, to preliminarily get the relevant factors, including the number of green building projects as a dependent variable and other influencing factors as independent variables, and to select, collect and process the variable data; the third step is to check the basic data and 
conduct default value processing; the fourth step is to set hypothesis and construct preliminary model; the fifth step is to estimate the linear regression model through SPSS software by using independent variable data analysed and collocated, and get the results of the model; the sixth step is to test the model and estimate the model, including the overall explanatory power R2, F test, significance $\mathrm{P}$ test, regression coefficient and $\mathrm{t}$ value test, model residual distribution test, D-W test and Variance-Inflation-Factor testing, and finally, the regression model is obtained; the seventh step is to give a summary of this chapter and explain in detail according to the results of the model. Detailed model analysis steps are discussed in the following section.

\section{Calculation of index weight of building construction greening}

According to the steps obtaining weight above, the corresponding comparison matrix is constructed by two-two comparing index level. Comparing the importance of the four first-order indexes with respect to the target layer, the intuitionistic fuzzy judgment matrix is obtained as follows $(E q .6)$ :

$$
A=\left[\begin{array}{l}
0.5(0.8,0.15)(0.1,0.9)(0.7,0.2) \\
(0.15,0.8) 0.5(0.1,0.9)(0.6,0.3) \\
(0.9,0.1)(0.9,0.1) 0.5(0.9,0.1) \\
(0.2,0.7)(0.3,0.6)(0.1,0.9) 0.5
\end{array}\right]
$$

To determine the subordinate degree of qualitative indicators, the form of questionnaire survey is adopted and the indicators are evaluated according to the scores of experts. The five language variables of "excellent", "good", "medium", "relative poor" and "poor" are used as the ratings. The leaders and management of the enterprise and a total of 20 experts from the floor and grass-roots staff evaluate the qualitative indicators in the evaluation system from the actual situation of Chinese buildings, and get the expert rating table shown in Table 3.

According to the above findings, the membership degree of a certain index refers to the frequency of occurrence of the index in a certain evaluation grade according to the survey results. Thus, the membership degree of the greening spirit and consciousness, green culture, and perfection and implementation of green system can be obtained, respectively: $\mathrm{R}_{11}=(0.8,0.1,0.1,0,0) ; \mathrm{R}_{12}=(0.6,0.2,0.2,0,0) ; \mathrm{R}_{13}=(0.7,0.2,0.1,0,0)$.

Table 3. Expert evaluation from of green qualitative evaluation index of China State Construction

\begin{tabular}{c|c|c|c|c|c|c}
\hline Number & Index evaluation & Excellent & Good & Medium & Relative poor & Poor \\
\hline $\mathrm{b}_{11}$ & Greening spirit and consciousness & 16 & 2 & 2 & 0 & 0 \\
$\mathrm{~b}_{12}$ & Green culture & 12 & 4 & 4 & 0 & 0 \\
$\mathrm{~b}_{13}$ & Perfection and implementation of green system & 14 & 4 & 2 & 0 & 0 \\
\hline
\end{tabular}

\section{Model application and case analysis}

\section{Exploration and practice of green building development in Shenzhen}

As the "first window" of the coastal developed cities and the reform and opening up, Shenzhen's green building development has created a remarkable "Shenzhen speed" of 
economic development. According to statistics, in 2017, "China's total GDP" was 1600.198 billion yuan, ranking fourth among the mainland cities; the per capita GDP was 149,497 yuan/person, ranking fifth among the mainland cities in China. The economic development situation has long been in the forefront of Chinese cities (Gao and Wang, 2018), laying an economic foundation for the development of "green building industry" in Shenzhen. According to the data, the real estate industry is the main direction (30-50\%) of fixed assets investment in Shenzhen in recent years and has maintained a growth trend for many years. The real estate investment volume has increased year by year since 2008 . Although the growth rate has declined from 2012, the overall view is that the real estate develops well. The development trend of production is good. The rapid development of the real estate industry has brought some economic benefits to Shenzhen. However, due to the inherent characteristics of resource consumption and pollution emission of construction activities, the real estate industry has been developing in the past with the mode of "high consumption and high discharge". How to reduce the consumption of natural resources and reduce the damage of the ecological environment in the process of industrial development has become a key research topic.

Under the contradiction of seeking "economic development" and "environmental resources" pressure, green buildings with the characteristics of resource conservation and environmental friendliness are eager to come out. All kinds of signs show that the development of green buildings is one of the necessary ways for the "sustainable economic development" of cities. The Shenzhen Municipal Government attaches great importance to the development of green buildings. At present, it is gradually building a green building construction system with four key points: laws and policies, project demonstration, financial support and technical support, which has contributed to the sustainable development of Shenzhen's economy, environment and society.

\section{Discussion}

\section{Shenzhen green building demonstration area and demonstration project lead construction}

\section{(1) The national green building demonstration area - Guangming New Area}

"Guangming" New Area is located in the northwest of Shenzhen City, with a total area of $156.1 \mathrm{~km}^{2}$. It is one of the "four new cities" put forward by Shenzhen City in 2007 for the development, and is positioned as "ecological high-tech industry new city". In 2008, the Shenzhen Municipal Government signed an agreement with the Ministry of Housing and Urban-Rural Construction to establish Guangming New Area as a pilot project for the construction of "National Green Building Demonstration Zone" to explore the experience of building green buildings in China. In January 2009, Shenzhen Construction Bureau and Guangming New Area Administrative Committee formulated the Guangming New Area Green Building Demonstration Project Construction Management Trial Rules to actively promote the construction of various demonstration projects in Guangming New Area, so as to promote the proportion of green buildings reaching more than $80 \%$ in $32 \mathrm{~km}^{2}$ green building demonstration areas.

\section{(2) Green building star demonstration project - Longyueju affordable housing}

Longyueju affordable housing is located in Longhua New Area of Shenzhen City, adjacent to Shenzhen North Railway Station. It is a large residential area invested by 
Shenzhen Municipal Government to solve the housing problems of talented people and low-and-middle-income families. It is one of the "ten livelihood projects" in Shenzhen in 2010, and it is also the largest comprehensive affordable housing project in Shenzhen up to now. Under the requirements of the 12th Five-Year Plan for Building Energy Conservation and Green Building in Shenzhen and the Development Plan for Housing Security in Shenzhen (2011-2015) for the overall green building construction in Shenzhen as well as the energy conservation and emission reduction targets of Longhua New Area and the construction of green building, the affordable housing of Longyueju, as the pilot project for affordable housing that first constructed following green building standard in Shenzhen, has set an example for Shenzhen to build a "green building capital" and a "green building demonstration city" (Fig. 5).

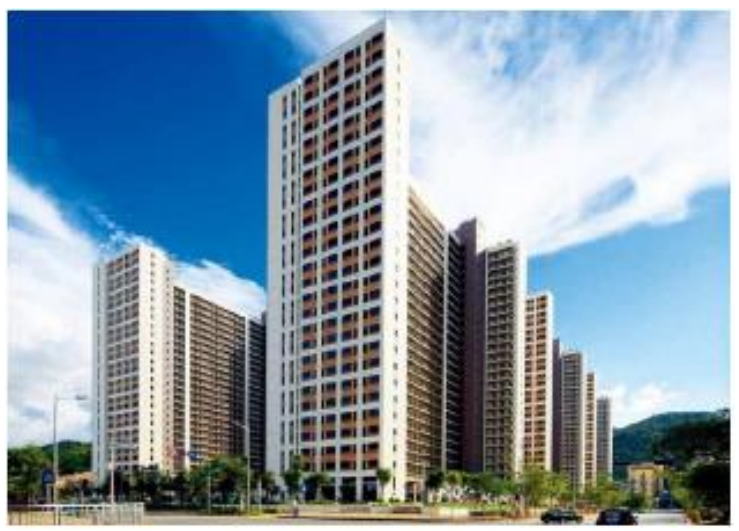

$\mathbf{a}$

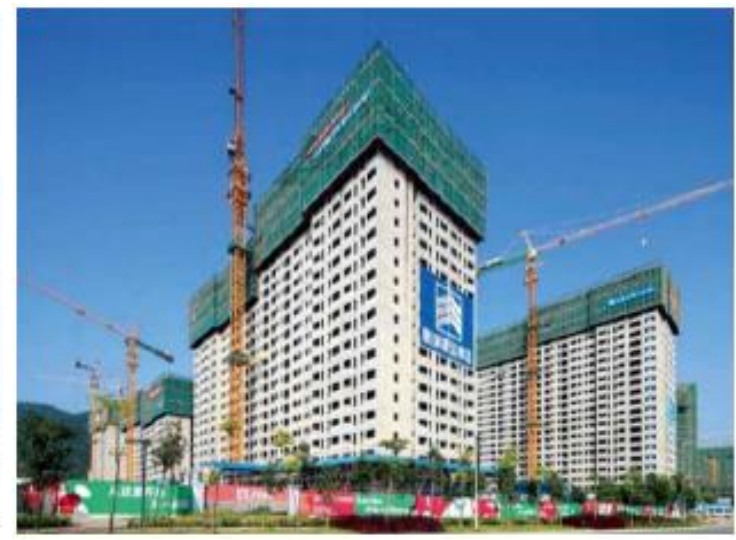

b

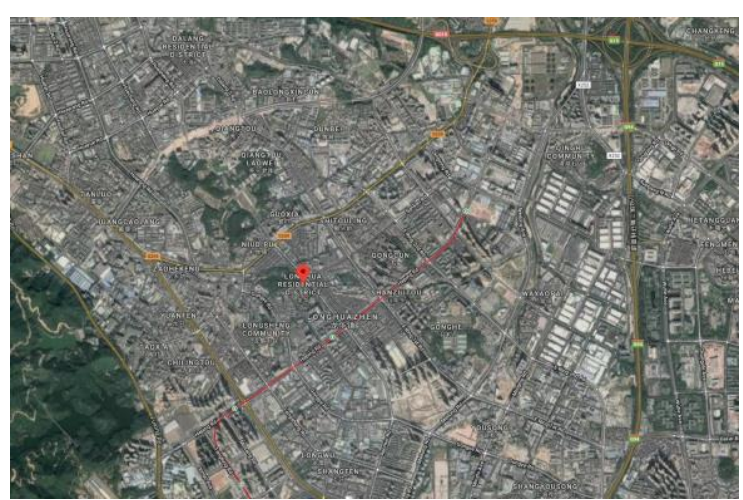

c

Figure 5. a. The real picture of Longyueju, from Baidu image. $\boldsymbol{b}$. Construction process and construction site, from Baidu image. c. The location of Longhua New Area, Shenzhen, from Google earth

\section{Conclusion}

Based on the above research results of green building development and its influencing factors, the main influencing factors behind the differences of urban green building development in China are analyzed through the multiple regression model of green building influence, and an empirical analysis is made through the experience of Shenzhen green building development. The following conclusions are drawn: 
(1) There are great differences between regions and between cities in the overall development of green building projects. At present, the green building market in China is mainly concentrated in the eastern coastal areas, as well as some municipalities directly under the central government and provincial capitals. It suggests that the development of green building in these cities is to some extent jointly affected by the urban economic environment, green building related policy environment and technology environment and other factors;

(2) The greening evaluation system and its evaluation model for sustainable development of housing construction enterprises are established by using intuitionistic fuzzy analytic hierarchy process. The empirical analysis of green evaluation of China Construction Corporation shows that the evaluation system and model established are both effective (Zhu, 2010). It is calculated that the greening level of China Construction Corporation is a super excellent greening grade.

(3) The strong government support has a significant impact on the development of green buildings in cities. Through the empirical study on the development of green buildings in Shenzhen, it is found that the government can effectively promote the development of urban green buildings by adopting a series of relevant laws and policies, combined with incentives, technology promotion, public publicity and other actions. Based on the analysis and summary of the construction experience of Shenzhen green building demonstration zone and demonstration project, the advanced experience of Shenzhen green building development can provide references for policy makers and implementers in other cities.

This paper combines data and theory through analysis method. Intuitionistic fuzzy analytic hierarchy process is an organic combination of intuitionistic fuzzy set theory and analytic hierarchy process. Based on the case of Shenzhen, this paper summarizes the factors affecting the development of green building, and provides methods and paths for future research.

Acknowledgement. Much gratitude is owed to the Zhuhai College of Jilin University for funding this study (Zhuhai College of Jilin University three levels of talent construction project funding ; Project of 100 people project training program for young teachers, Zhuhai College of Jilin University) and providing relevant research assistance.

\section{REFERENCES}

[1] Aggarwal, R., Singh, S. (2018): A hybrid approach for supplier selection based on revised data envelopment analytic hierarchy process. - International Journal of Operational Research 31(4): 478-509.

[2] Alwan, Z., Jones, P., Holgate, P. (2017): Strategic sustainable development in the uk construction industry, through the framework for strategic sustainable development, using building information modelling. - Journal of Cleaner Production 140(1): 349-358.

[3] Baden, D., Prasad, S. (2016): Applying behavioural theory to the challenge of sustainable development: using hairdressers as diffusers of more sustainable hair-care practices. Journal of Business Ethics 133(2): 1-15.

[4] Broman, G. I., Robèrt, K. H. (2017): A framework for strategic sustainable development. - Journal of Cleaner Production 140: 17-31.

[5] Brown, L. D. (1991): Bridging organizations and sustainable development. - Human Relations 44(8): 807-831. 
[6] Chong, H. Y., Wang, X. (2016): The outlook of building information modeling for sustainable development. - Clean Technologies \& Environmental Policy 18(6): 1-11.

[7] Edgren, L. (2017): Contemporary Conservation Theory for Sustainable Development of Cultural Heritage Objects. - International Journal of the Inclusive Museum 10(1): 1-8.

[8] Gao, G., Wang, T. (2018): Study on the relationship between the opening of environmental tax and the prevention and control of air pollution in China. - American Institute of Physics Conference Series 1944. https://doi.org/10.1063/1.5029789.

[9] Hu, A. (2018): China's Road and China's Dream. - Springer Nature, Singapore.

[10] Huang, X., Shi, X. (2017): Evaluation of supply capacity of food emergency logistics in natural disaster. - International Conference on Logistics, Informatics and Service Sciences, 24-27 July 2016. 10.1109/LISS.2016.7854588.

[11] Kopnina, H. (2016): Victims of unsustainability: a challenge to sustainable development goals. - International Journal of Sustainable Development \& World Ecology 23(2): 113121.

[12] Li, B., Gao, Y. (2015): Application of the improved fuzzy analytic hierarchy process for landslide hazard assessment based on RS and GIS. - International Conference on Intelligent Earth Observing and Applications (Vol. 9808). International Society for Optics and Photonics. DOI: 10.1117/12.2207381.

[13] Pang, B., Lin, B., Lv, Q., Liu, Y. (2016): The application of fuzzy theory in the evaluation and recruitment of university interpretation teachers. - International Conference on Natural Computation, Fuzzy Systems and Knowledge Discovery (pp. 1108-1113), IEEE.

[14] Rahmati, O., Pourghasemi, H. R., Zeinivand, H. (2016): Flood susceptibility mapping using frequency ratio and weights-of-evidence models in the Golastan province, Iran. Geocarto International 31(1): 42-70.

[15] Rodríguez, A., Ortega, F., Concepción, R. (2016): A method for the evaluation of risk in it projects. - Expert Systems with Applications 45(C): 273-285.

[16] Shafiei, M. W. M., Abadi, H., Osman, W. N. (2017): The indicators of green buildings for Malaysian property development industry. - International Journal of Applied Engineering Research 12(10): 2182-2189.

[17] Sharma, R., Fantin, A. R., Prabhu, N., Guan, C., Dattakumar, A. (2016): Digital literacy and knowledge societies. - Telecommunications Policy 40(7): 628-643.

[18] Stafford-Smith, M., Griggs, D., Gaffney, O., Ullah, F., Reyers, B., Kanie, N. et al. (2017): Integration: the key to implementing the sustainable development goals. - Sustainability Science 12(6): 911-919.

[19] Takahashi, I. (1990): AHP applied to binary and ternary comparisons. - Journal of the Operations Research Society of Japan 33(3): 199-206.

[20] Wang, X. (2017): 50. Research on cost benefit index system of green reconstruction based on existing buildings. - Boletín Técnico 55(10): 339-346.

[21] Wu, P., Song, Y., Shou, W., Chi, H., Chong, H. Y., Sutrisna, M. (2017): A comprehensive analysis of the credits obtained by LEED 2009 certified green buildings. Renewable \& Sustainable Energy Reviews 68: 370-379.

[22] Wu, S. R., Fan, P., Chen, J. (2016): Incorporating culture into sustainable development: A cultural sustainability index framework for green buildings. - Sustainable Development 24(1): 64-76.

[23] Wuelser, G., Pohl, C. (2016): How researchers frame scientific contributions to sustainable development: a typology based on grounded theory. - Sustainability Science 11(5): 789-800.

[24] Xiu, Y., Fu, Y., Cui, W. (2017): Research on the sustainable development of china's foreign trade enterprises under the background of the change of the macroeconomic situation of the international economy. - Journal of Computational \& Theoretical Nanoscience 14(6): 2733-2738. 
[25] Yang, F. (2015): Contemporary construction of ecological civilization: from ecological crisis to ecological governance. - Chinese Journal of Urban \& Environmental Studies 03(04): 1550030.

[26] Yang, G., Zhou, Y. (2010): Research on the government incentive of green buildings in China. - International Conference on Management and Service Science (pp. 1-5), IEEE.

[27] Yang, Y., Xu, W., Jing, P. (2012): The fuzzy comprehensive evaluation of financial ecological environment of Kunming. - International Conference on Information Management, Innovation Management and Industrial Engineering (Vol. 2, pp. 62-65), IEEE.

[28] Yuan, Y., Yu, X., Yang, X., Xiao, Y., Xiang, B., Wang, Y. (2017): Bionic building energy efficiency and bionic green architecture: a review. - Renewable \& Sustainable Energy Reviews 74: 771-787.

[29] Zhang, C., Li, W., Yang, H. (2012): A new drug risk assessment model of comprehensive hospitals. - International Conference on Biomedical Engineering and Biotechnology (pp. 1165-1168), IEEE Computer Society.

[30] Zhou, S. (2010): The transformation and thinking of management concept in construction industry based on sustainable development. - International Conference on Management and Service Science (pp. 1-5), IEEE.

[31] Zhou, T., Wang, Y. P., Wang, F. (2009): A dynamic assessment of Ecological Footprint and Biocapacity in Guangzhou using RS and GIS. - Urban Remote Sensing Event (pp. 19), IEEE.

[32] Zhou, Y., Zhao, X. G. (2013): Safety Management of Oil Depot Based on Fuzzy Analytic Hierarchy Process. - In: 2012 International Conference on Information Technology and Management Science (ICITMS 2012) Proceedings (pp. 67-72). Springer, Berlin, Heidelberg.

[33] Zhu, W., Shi, M. (2017): Study on labor relations from the perspective of "The belt and road initiative". - International Conference on Logistics, Informatics and Service Sciences, IEEE.

[34] Zhu, Y. Y. (2010): Research on the evaluation of customer satisfaction under B2C ecommerce. - International Conference on Networking and Digital Society (Vol. 1, pp. 601-604), IEEE. 